\section{Water-bottle heart}

A 84-year-old woman presented to the emergency department with complaints of progressive shortness of breath and generalized edema over the prior 2 months. She had a history of hypertension, chronic obstructive pulmonary disease and persistent atrial fibrillation (AF). On admission, her blood pressure was $140 / 95 \mathrm{~mm} \mathrm{Hg}$ and heart rate was 75 beats per minute with an irregular pulse. Physical examination revealed severe jugular venous distention (Fig. 1), grade 4 peripheral edema and ascites and a grade $3 / 6$ holosystolic murmur that augmented with inspiration was noted at the left lower sternal border. Electrocardiography demonstrated AF rhythm and postero-

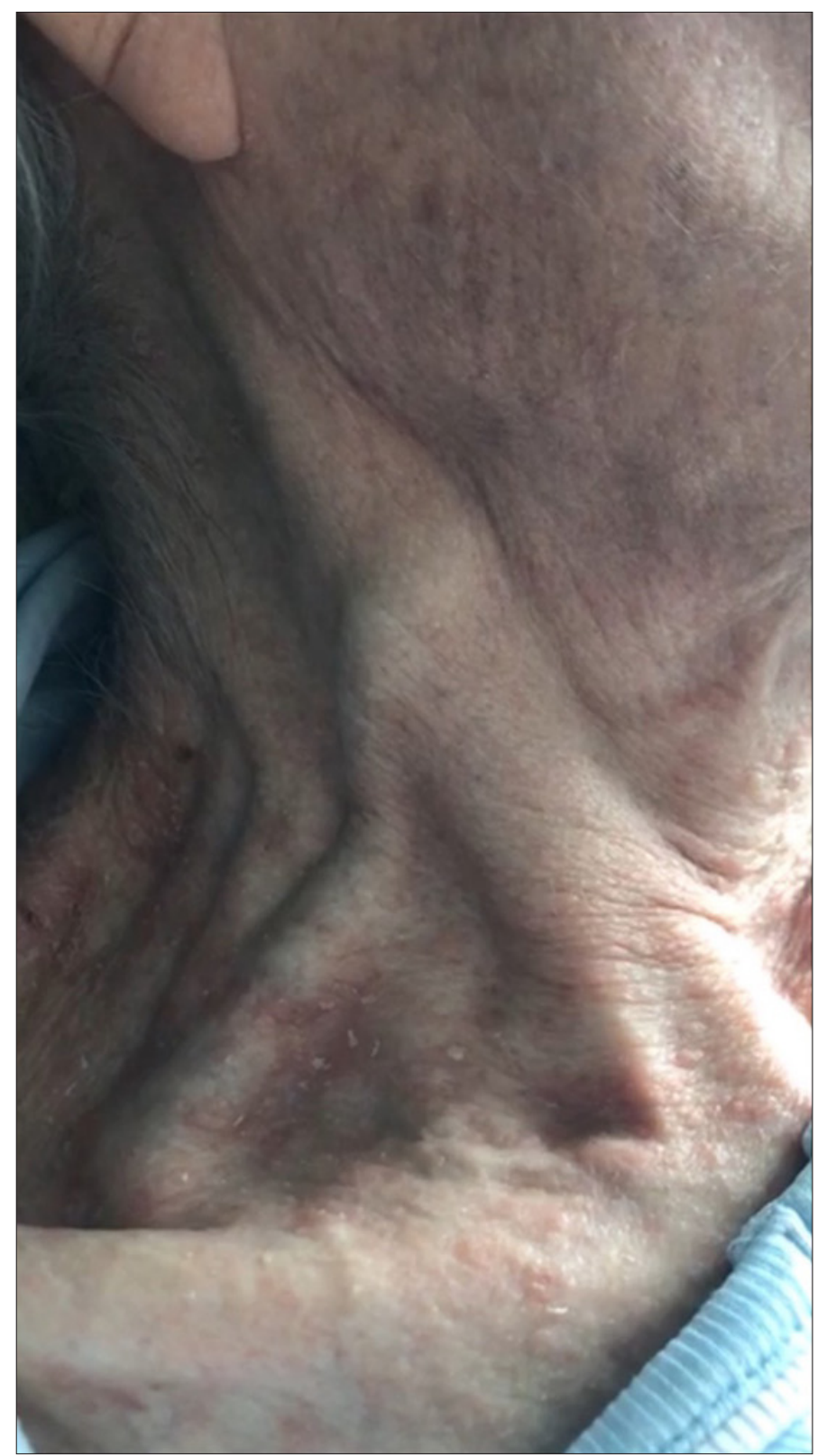

Figure 1. Severe jugular venous distention is shown

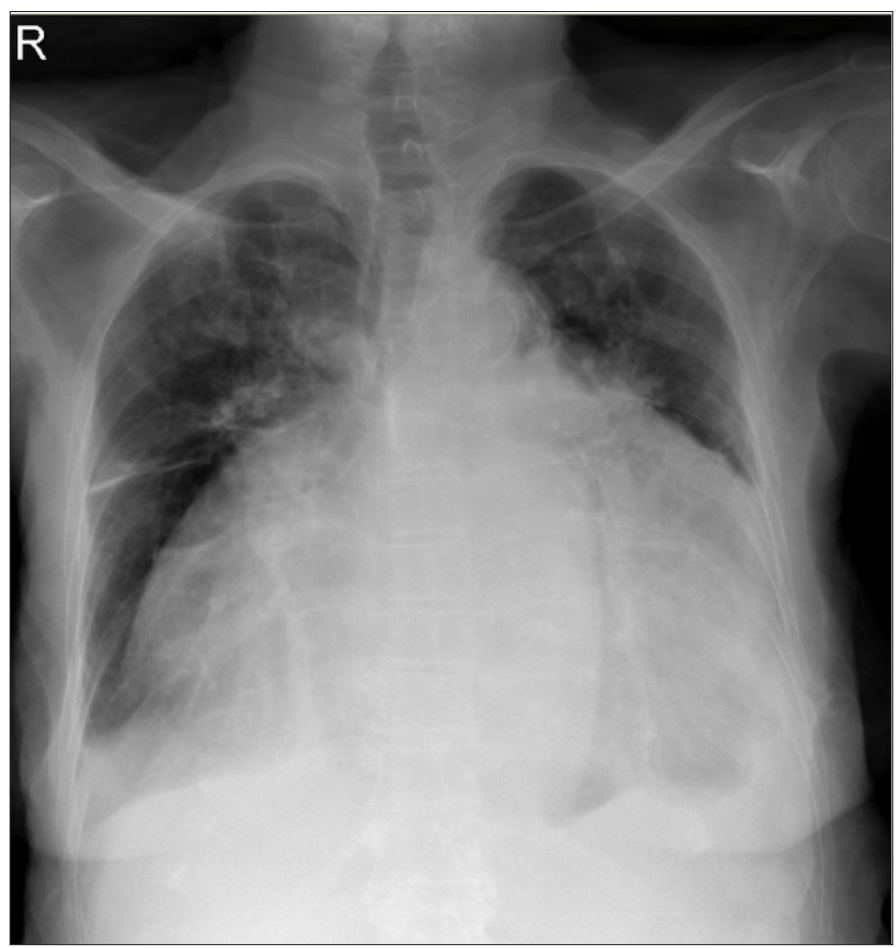

Figure 2. Posteroanterior chest X-ray showing a globular heart with "water-bottle" configuration and evidence of pulmonary edema

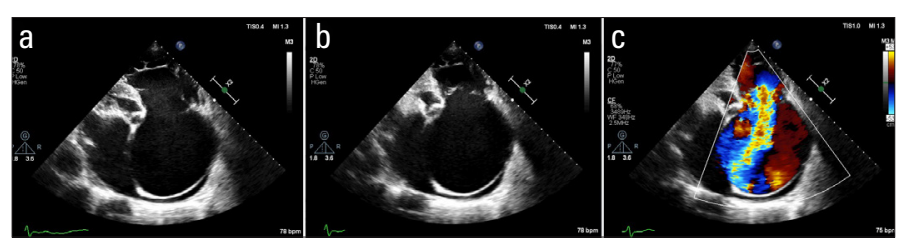

Figure 3. Transthoracic echocardiography from modified apical four chamber view showing hugely dilated right atrium (a-c), and malcoaptation of the tricuspid-valve leaflets as a result of annular dilatation (b), with resultant severe tricuspid regurgitation (c)

anterior chest X-ray showed a globular heart (with cardiothoracic ratio of 0.9 ) with "water-bottle" configuration and evidence of pulmonary edema (Fig. 2). Transthoracic echocardiography demonstrated hugely dilated right atrium $(11 \times 13 \mathrm{~cm})$ (Fig. 3) and malcoaptation of the tricuspid-valve leaflets as a result of annular dilatation, with resultant severe tricuspid regurgitation. Moderate mitral regurgitation, dilated left atrium, enlarged $(60 \mathrm{~mm})$ right ventricle, dilated $(29 \mathrm{~mm})$ non collapsing inferior vena cava and elevated $(70 \mathrm{~mm} \mathrm{Hg})$ pulmonary artery systolic pressure were also noted. Left ventricular ejection fraction was $60 \%$. Intravenous diuretic agents were used to normalize volume status and symptoms resolved completely.

The "water-bottle" sign refers to the radiographic appearance of the cardiac silhouette which is commonly associated with pericardial effusion, but it can also be present in severe cavity dilation secondary to valvular heart disease.

Informed consent: Written informed consent was obtained from the patient. 
Yalçın Velibey (D), Feyza Mollaalioğlu (D), Semih Eren (D),

Kemal Emrecan Parsova (iD

Department of Cardiology, Siyami Ersek Thoracic and Cardiovascular Surgery Center, Training and Research Hospital; İstanbul-Turkey
Address for Correspondence: Dr. Yalçın Velibey,

Siyami Ersek Göğüs Kalp ve Damar Cerrahisi Merkezi,

Eğitim ve Araştırma Hastanesi, Kardiyoloji Bölümü, İstanbul-Türkiye

Phone: +90 5464574646

E-mail: dr_yalchin_dr@yahoo.com.tr

(C) Copyright 2021 by Turkish Society of Cardiology -

Available online at

www.anatoljcardiol.com

DOI:10.5152/AnatolJCardiol.2021.25274 